\title{
Pregnancy luteoma accompanied by cervical insufficiency: a case report
}

Xinyi Wang ${ }^{1}$, Xin $\mathrm{Li}^{1}$, Chunyan $\mathrm{Shi}^{1}$, and Huixia Yang ${ }^{2}$

${ }^{1}$ Affiliation not available

${ }^{2}$ Peking University 1st hospital

August 14, 2020

\section{Hosted file}

Pregnancy Luteoma Accompanied by Cervical Insufficiency - BJOG.doc available at https: //authorea.com/users/350935/articles/475639-pregnancy-luteoma-accompanied-by-cervicalinsufficiency-a-case-report

\section{Hosted file}

Table1.doc available at https://authorea.com/users/350935/articles/475639-pregnancy-luteomaaccompanied-by-cervical-insufficiency-a-case-report

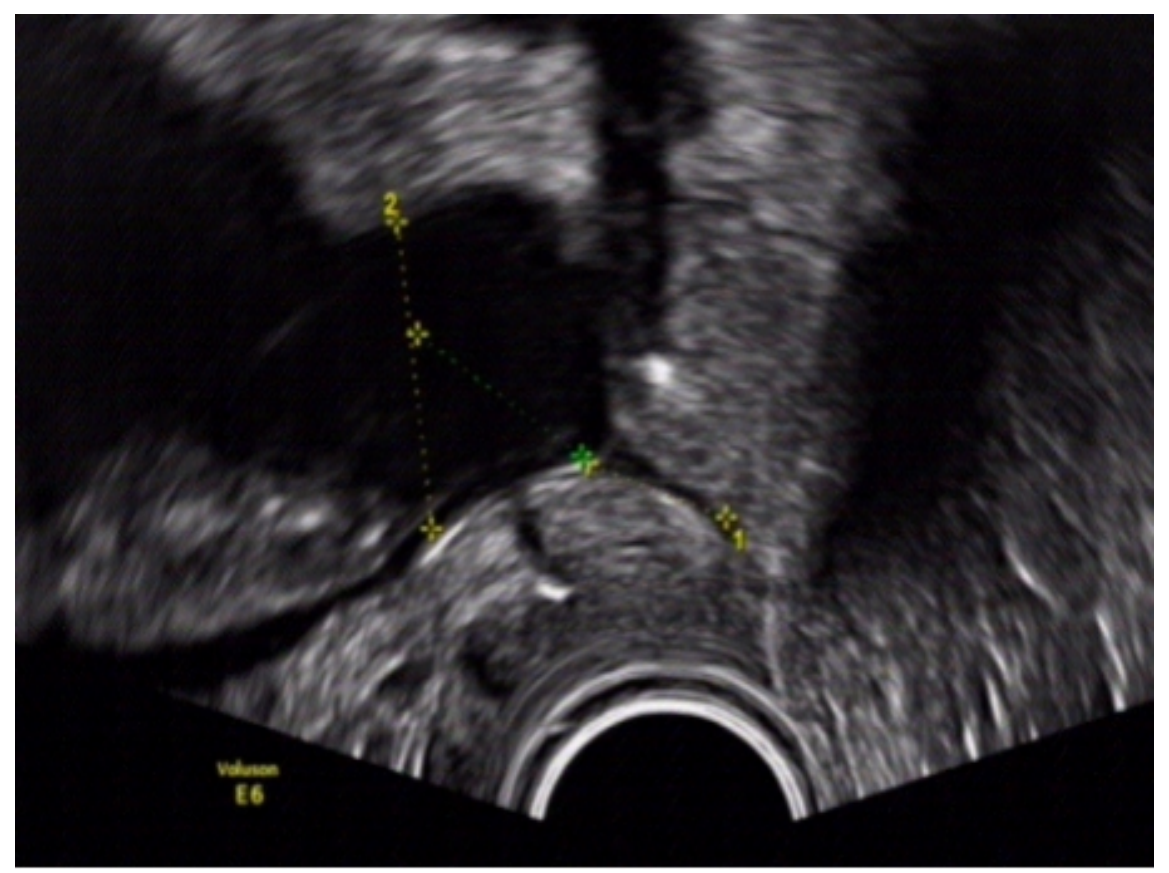

